\title{
A implementação de a gente não sujeito no sertão alagoano
}

\section{The implementation of a gente not subject in the backwoods of Alagoas}

\author{
José Manoel Siqueira da Silva * \\ Universidade Federal de Alagoas \\ Delmiro Gouveia, Alagoas, Brasil
}

Elyne Giselle de Santana Lima Aguiar Vitório**

Universidade Federal de Alagoas

Delmiro Gouveia, Alagoas, Brasil

\begin{abstract}
Resumo: No presente estudo, interessamo-nos em estudar a implementação de a gente nas funções de não sujeito na fala de sertanejos alagoanos. Assim, observamos a alternância entre nós e a gente pronomes, levando em consideração as funções de acusativo, dativo, (oblíquo) complemento e (oblíquo) adjunto. Ainda, procuramos saber qual a frequência de uso de cada forma, quais fatores sociais e/ou linguísticos condicionam o uso da variável e, por fim, questionar se estamos diante de uma variação estável ou uma mudança em curso. Baseado nisso, o presente trabalho leva em consideração o que é proposto pela Teoria da Variação e Mudança Linguística (LABOV, 2008), associados aos estudos de Lopes (2002, 2004), Ramos, Bezerra \& Rocha (2009), Vianna \& Lopes (2012, 2013), Vitório (2017). Os dados analisados foram extraídos a partir do banco de dados do Projeto A Língua Usada no Sertão Alagoano (LUSA) e rodados no programa computacional GoldVarb X. Após a análise dos dados, concluímos que, embora haja a variação pronominal nas funções estudadas, $\mathrm{O}$ pronome conservador encontra-se com um maior índice de realização, havendo pouca realização do a gente e que essa variação é condicionada apenas por fatores internos, além de apresentar uma variação estável.
\end{abstract}

Palavras-chave: Variação. 1PP. Não sujeito. Sertão Alagoano.

Abstract: In the present study, we are interested in studying the implementation of a gente in the functions of non-subject in the speech of backwoods of Alagoas. Thus, we observe the alternation between nós and a gente pronouns, taking into account the functions of accusative, dative, (oblique) complement and (oblique) adjunct. Also, we try to know how often to use each form, what social and/or linguistic factors condition the use of the variable and, finally, to question whether we are facing a stable variation or a change in progress. Based on this, the present work takes into account what is proposed by the Theory of Variation and Linguistic Change (LABOV, 2008), associated with the studies of Lopes (2002, 2004), Ramos, Bezerra \& Rocha (2009), Vianna \& Lopes (2012, 2013), Vitório (2017b). The data analyzed were extracted from the database of the project the language used in the backwoods of Alagoas and run in the computer program GoldVarb X. After the analysis of the data, we conclude that, although there is a pronominal variation in the functions studied, the conservative pronoun has a higher achievement index, with little accomplishment of the a gente and that this variation is conditioned only by internal factors, besides stable variation.

Keywords: Variation. 1PP. Not-subject. Backwoods of Alagoas.

* Graduando em Letras pela Universidade Federal de Alagoas - Campus Sertão e bolsista PIBIC/CNPq. E-mail: manoel.siqueira77@hotmail.com.

** Doutora em Linguística e professora da Universidade Federal de Alagoas - Campus Sertão.E-mail: elyne.vitorio@gmail.com. 


\section{INTRODUÇÃO}

Diversas pesquisas feitas no Brasil com base nos pressupostos da teoria laboviana ajudam no avanço de discussões sobre o uso real da língua portuguesa feita pelos brasileiros. Dentre as principais pesquisas feitas nesse cenário nacional, podemos listar os estudos feitos sobre o quadro pronominal do português brasileiro. Mais restritamente, podemos listar os estudos feitos sobre a variação pronominal na fala do sertão alagoano (cf. PORTO SILVA, 2017; SILVA; 2017; FEITOSA, 2017). As pesquisas feitas na região têm mostrado um maior uso da variante não padrão na posição de sujeito em detrimento da variante padrão (você $>$ tu, a gente $>$ nós).

Entretanto, mesmo com tal mapeamento feito na área, ainda não é possível aferir se tais pronomes estão realmente inseridos em todos os contextos sintáticos no falar da comunidade em questão. Com o intuito de compreender como está sendo feita a utilização pronominal na região do sertão alagoano, é preciso que sejam investigados os outros ambientes nos quais os pronomes podem se inserir. Assim, entra aqui a ideia do presente estudo em relação à implementação do pronome a gente na comunidade de fala do sertão alagoano.

De tal modo, diante da perspectiva de a língua ser variável e de haver diferentes formas de dizer algo com o mesmo valor semântico, guiamos o nosso trabalho através da ideia de que o pronome a gente não adentrou no português brasileiro apenas na função sintática de sujeito, introduzindo-se também em outras funções sintáticas - complemento e adjunto. Assim, tendo em vista tal ideia, buscamos responder o seguinte problema na pesquisa: há variação entre nós e a gente nas funções de não sujeito no sertão alagoano?

Para que pudéssemos realizar o que objetivamos, nos filiamos ao que prega a Teoria da Variação e Mudança Linguística (LAVOV, 2008), buscando responder o que nosso trabalho propõe. Diante das variantes da nossa pesquisa, focamos em compreender o problema da restrição linguística, analisando, além da frequência de variação, os elementos que condicionam o uso de determinada variante, sejam esses condicionantes linguísticos e/ou sociais.

Para a análise dos dados, recorremos ao banco de dados A Língua Usada no Sertão Alagoano - LUSA (VITÓRIO, 2017a) ${ }^{1}$, composto por 96 entrevistas sociolinguísticas, estratificadas segundo as variáveis sexo/gênero (masculino/feminino), faixa etária (F1: 18 a 29 anos; F2: 30 a 44 anos; e F3: acima de 44 anos) e escolaridade (E0: analfabeto/semianalfabeto; E1: ensino fundamental; E2: ensino médio; e E3: ensino superior) e utilizamos o programa computacional GoldVarb X (SANKOFF; TAGLIAMONTE; SMITH, 2005).

Para atingir os nossos objetivos propostos, na próxima seção, expomos um breve percurso do pronome a gente no português brasileiro, na seguinte seção, abordamos o que dizem algumas pesquisas sociolinguísticas sobre a implementação de a gente em contextos sintáticos de complementação e adjunção, em seguida, descrevemos os resultados obtidos

${ }^{1}$ Este trabalho faz parte do projeto A Língua Usada no Sertão Alagoano, submetido e aprovado pelo Comitê de Ética e Pesquisa da Universidade Federal de Alagoas, sob número de parecer 1.073.208. 
para o processo de variação por nós estudado, observando tanto a variável dependente quanto as variáveis independentes, e, por fim, tecemos nossas considerações finais.

\section{O PRONOME A GENTE NO PORTUGUÊS BRASILEIRO}

A forma pronominal a gente passou por um processo de mudança linguística no percurso histórico da Língua Portuguesa. Seu processo de gramaticalização foi lento e gradual. Originando-se do substantivo gente, o pronome inovador de primeira pessoa do plural (1PP) acabou mudando e resultando na forma atual a gente. Segundo Lopes (2002; 2004), a forma pronominal a gente fez suas primeiras aparições, com níveis bastante escassos, em textos do século XIII. Entretanto, foi apenas no século XVI que ela começou a ganhar terreno.

De acordo com a autora, "só foram localizadas ocorrências de a gente como pronome no século XVIII. Antes disso, há exemplos esporádicos em que a forma a gente apresenta ambiguidade interpretativa, ou seja, tanto pode ser considerada sinônimo de “pessoas" quanto variante de nós” (LOPES, 2002, p. 01). Apenas no século XIX começa realmente a ocorrer o processo de gramaticalização, aqui entendido como o ato de um item lexical se tornar um item gramatical, ex: gente $>$ a gente.

Em seu início, a forma apresentava sentido tanto para "pessoas", excluindo o "eu" do discurso, quanto para "pessoas", inserindo o "eu", relacionando-se com o pronome nós. Essas ocorrências, com o sentido de ambiguidade, tornaram-se frequentes no decorrer do tempo, do mesmo modo em que a forma começa a ser usada com mais frequência pelos falantes.

Com a ascendência e a iminência do processo de gramaticalização da forma a gente, os casos ambíguos começam a diminuir, deixando a interpretação apenas de a gente como forma pronominal, variante de nós. Através de seu estudo, Lopes (2002) constatou, conforme o gráfico 1, a alteração semântica do pronome a gente no seu processo evolutivo, mostrando que, a partir do século XVII, os usos de a gente em todas as formas começaram a apresentar diferenças relacionadas ao seu comportamento nos séculos anteriores.

Gráfico 1: Percurso histórico de gente (substantivo) > a gente (pronome)

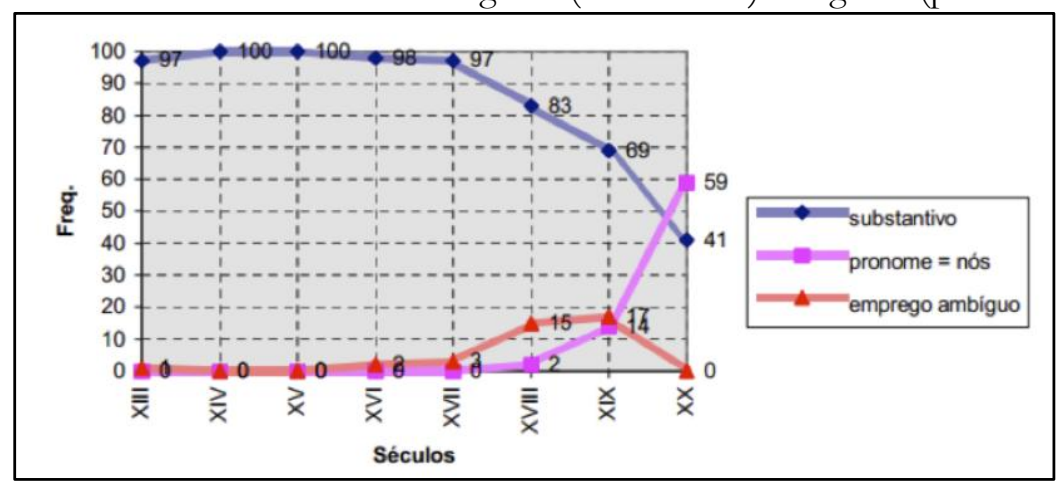

Fonte: Lopes (2002, p. 3) 
Entretanto, além dessas mudanças apresentadas relacionadas ao processo de pronominalização, a introdução da variante a gente no sistema pronominal do Português acabou alterando outros fatores no sistema linguístico, ou seja, houve também uma mudança em relação ao uso dos pronomes em relação às funções sintáticas. Desse modo, o pronome a gente começou a disputar, em um processo de variação com a forma conservadora nós, as diferentes funções sintáticas presentes no sistema do Português sujeito, complemento e adjunto.

O que antes se resumia a apenas uma forma de primeira pessoa do plural na posição de sujeito, agora se estende a duas e que, consequentemente, disputam na realização pronominal em outras funções sintáticas, tais como as de dativo, acusativo, (oblíquo) complemento e (oblíquo) adjunto. Dessa forma, além de ter havido o processo de gramaticalização do a gente no português brasileiro, houve um rearranjo sintático, possibilitando o uso do pronome inovador em diferentes funções sintáticas, concorrendo com o pronome conservador nós.

Assim, podemos considerar que o pronome a gente adentrou no sistema pronominal do Português através de um processo de gramaticalização, efetuando-se no século XIX, e que, através desse processo, o pronome começou a disputar com a forma conservadora em diferentes funções sintáticas além da posição de sujeito.

\section{VARIAÇÃO NÓS/A GENTE NAS FUNÇÕES DE NÃO SUJEITO NO PB}

Ao nos debruçarmos sobre determinados fenômenos que ocorrem na língua, é comum encontrarmos pesquisas já realizadas sobre os temas estudados. Tais pesquisas funcionam como forma para melhor dar suporte ao trabalho estudado - ajudando a refutar (ou não) as ideias propostas -, ou servindo como ponto norteador dos nossos pensamentos. Diante dessa perspectiva, a presente seção tratará de explanar pesquisas sociolinguísticas feitas sobre o tema por nós estudado, utilizando as discussões de Vianna \& Lopes (2012) e Vitório (2017b).

$\mathrm{Em} A$ competição entre nós e a gente nas funções de complemento e adjunto: desvendando outras portas de entrada para o pronome inovador, Vianna \& Lopes (2012) observaram que a variação nós e a gente pode ser entendida como um processo de mudança, condicionada pelas variáveis relações gramaticais, tipos de núcleo, paralelismo formal e semântico, faixa etária e escolaridade, com a gente sendo mais frequente nos seguintes contextos: (oblíquo) complemento, núcleo verbal, antecedido por a gente em outras funções sintáticas, falantes mais jovens e do ensino médio.

As autoras pontuam que a implementação de a gente ocorre maior com frequência no núcleo verbal, conforme tabela 1 . Assim, temos, na função de acusativo, o maior resultado no núcleo verbal, com o a gente sendo realizado em $25 \%$ contra $18 \%$ do nós. Já no núcleo nominal, percebemos um percentual maior de nós em relação à função de (oblíquo) adjunto, tendo o pronome conservador um percentual de $86 \%$ contra apenas $9 \%$ do a gente, dando a ideia de que, nessa função sintática, os falantes ainda preferem o uso da forma conservadora. 
Tabela 1: Distribuição da 1PP nas relações gramaticais de não-sujeito pelos tipos de núcleo

\begin{tabular}{|l|c|c|c|c|c|c|c|c|}
\hline \multicolumn{3}{c|}{ Acusativo } & \multicolumn{2}{c|}{ Dativo } & \multicolumn{2}{c|}{ (Obl.) Compl. } & \multicolumn{2}{c|}{ (Obl.) Adjunto } \\
\hline & nós & a gente & nós & a gente & nós & a gente & nós & a gente \\
\hline Núcleo & - & - & - & - & - & $7 / 145$ & $125 / 145$ & $13 / 145$ \\
nominal & & & & & & $5 \%$ & $86 \%$ & $9 \%$ \\
\hline Núcleo & $14 / 77$ & $19 / 77$ & $4 / 77$ & $7 / 77$ & $1 / 77$ & $12 / 77$ & $7 / 77$ & $13 / 77$ \\
verbal & $18 \%$ & $25 \%$ & $5 \%$ & $9 \%$ & $1 \%$ & $15 \%$ & $9 \%$ & $17 \%$ \\
\hline
\end{tabular}

Fonte: Vianna e Lopes (2012, p. 147)

Vitório (2017b), no trabalho $A$ realização dos pronomes nós e a gente na função de sujeito $e$ nas funções de complemento e adjunto na cidade de Maceió/ AL, pontua que, na posição de sujeito, a gente é a variante preferida - 84\% versus $16 \%$ de nós, mas, nas posições de complemento e adjunto, as formas de nós ainda são as selecionadas $-61 \%$ versus $39 \%$ de a gente. Em relação à variação nas funções de não sujeito, a autora mostra que há o condicionamento das variáveis tipos de núcleo, relações gramaticais, paralelismo formal, sexo/gênero e escolaridade.

Segundo a autora, a implementação de a gente não sujeito na fala maceioense é mais frequente nos seguintes contextos, a saber: núcleo verbal; funções de acusativo e (oblíquo) adjunto, mostrando, conforme tabela 2, que a gente é mais frequente na função acusativa, que pertence ao núcleo verbal - 40\%, o que parece indicar que os dados caminham na mesma direção dos dados apontados por Vianna \& Lopes (2012) para a fala carioca; contexto de paralelismo formal, principalmente quando a gente é antecedido por a gente em outras funções sintáticas; entre os falantes do sexo feminino e menos escolarizados.

Tabela 2: Distribuição da 1PP nas relações gramaticais de não-sujeito pelos tipos de núcleo

\begin{tabular}{|c|c|c|c|c|c|c|c|c|}
\hline & \multicolumn{2}{|c|}{ Acusativo } & \multicolumn{2}{|c|}{ Dativo } & \multicolumn{2}{|c|}{ (Oblíquo) Compl. } & \multicolumn{2}{|c|}{ (Oblíquo) Adjunto } \\
\hline & nós & a gente & nós & a gente & nós & a gente & nós & a gente \\
\hline Núcleo nominal & - & - & - & - & $\begin{array}{c}4 / 80 \\
5 \%\end{array}$ & $\begin{array}{c}3 / 80 \\
4 \%\end{array}$ & $\begin{array}{c}62 / 80 \\
77 \%\end{array}$ & $\begin{array}{c}11 / 80 \\
14 \%\end{array}$ \\
\hline Núcleo verbal & $\begin{array}{c}2 / 48 \\
4 \%\end{array}$ & $\begin{array}{c}19 / 48 \\
40 \%\end{array}$ & $\begin{array}{l}9 / 48 \\
19 \%\end{array}$ & $\begin{array}{c}2 / 48 \\
4 \%\end{array}$ & $\begin{array}{c}1 / 48 \\
2 \%\end{array}$ & $\begin{array}{l}5 / 48 \\
10 \%\end{array}$ & - & $\begin{array}{c}10 / 48 \\
21 \%\end{array}$ \\
\hline
\end{tabular}

Fonte: Vitório (2017b, p. 133)

O que podemos ver através dos estudos sociolinguísticos aqui apresentados é que o pronome inovador está em constante processo de variação com o pronome conservador, havendo casos em que o a gente é a forma mais utilizada nas funções sintáticas, representando uma mudança em curso no sistema linguístico quanto ao uso pronominal nas posições de não sujeito. Esses estudos nos levam a pressupor que o mesmo pode estar acontecendo na região do sertão alagoano, dando aporte para os possíveis resultados que obtivermos e ajudando-nos a observar que a variação entre nós e 
a gente não é um processo isolado, e sim algo que está ocorrendo em diversas regiões onde é falado o português brasileiro.

\section{ANÁLISE E DISCUSSÃO DOS DADOS}

\subsection{Variável dependente}

Pesquisas sociolinguísticas feitas com base na amostra do LUSA constataram que o pronome de 1 PP preferencial do sertão alagoano é o inovador a gente. Feitosa (2017) observou que, na posição de sujeito, há um total de realização de 843 dos pronomes de $1 \mathrm{PP}$, sendo 197 realizações do pronome nós e 646 do pronome a gente, estabelecendo uma predominância do a gente com $77 \%$ contra apenas $23 \%$ do nós. Silva (2017) constatou um total de 73 realizações de pronomes de $1 \mathrm{PP}$, sendo 16, representando $22 \%$, para o pronome nós e 57 , representando $78 \%$, para o pronome a gente, compreendendo que os falantes não escolarizados preferem a gente.

Entretanto, mesmo com esse preferencial em relação ao pronome inovador na posição de sujeito, há de se perguntar se o mesmo está ocorrendo nas funções de não sujeito. Como já tratado, com o processo de gramaticalização que houve com o pronome inovador, houve um rearranjo no sistema linguístico, possibilitando que o a gente ocupasse funções sintáticas que antes ficavam apenas para o pronome nós, como podemos observar nos exemplos (1), (2), (3) e (4).

(1) porque eu acho melhó né - é melhor pá gente do que andá num canto estranho só isso mermo L2

(2) se eu já tipo me expus a um risco? a: é a própria vida da gente é um risco né? ((risos)) diariamente - a gente já vem trabalha $\mathrm{x}$ fazê as coisas e é com risco mais L10

(3) Olha - trabalha hoje: em escola sendo professô - eu acredito que seja uma das profissões mais difícil - que a gente pode tê né? Por conta da falta de intere::sse dos alu::nos - da administração:o dos governa::ntes - São $\mathrm{N}$ fatores que a gente se fô olhá às vezes deixa a gente até para baixo - /mais, mas/ sempre tem seus lados positi:vos e são esses que às vezes deixa a gente mais à vontade no que faz L14

(4) acho que ele tá fazendo um bom traba::lho - eu go:sto do que ele tá fazendo com a gente L17

Desse modo, após a análise dos dados no programa computacional GoldVarb X (SANKOFF; TAGLIAMONTE; SMITH, 2005), obtivemos um total de 210 realizações dos pronomes de 1PP nas funções de não sujeito nos dados do LUSA, sendo 167 realizações do pronome nós, para 43 realizações do pronome a gente. Assim, o pronome conservador representa um percentual de $80 \%$, tendo a maior realização, enquanto o pronome inovador teve apenas $20 \%$, sendo menos selecionado pelos falantes da região na posição estudada, conforme gráfico 2 . 


\section{das Letras}

Gráfico 1: Realização do nós e a gente nas funções de não sujeito

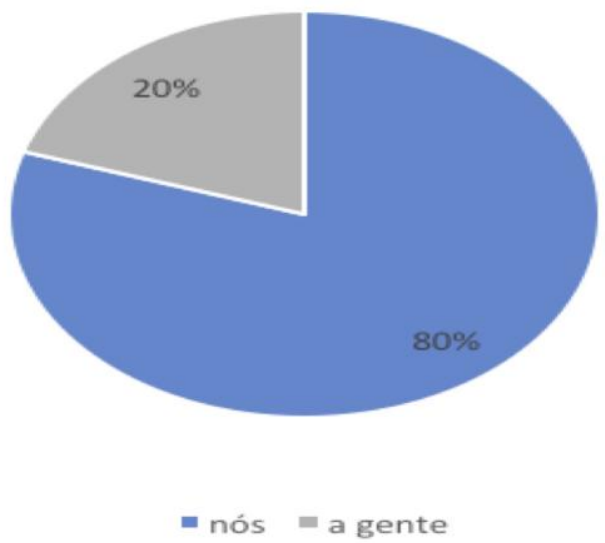

Fonte: elaborado pelos autores

Embora os resultados apresentem que há uma regra variável para o fenômeno (cf. LABOV , 2008), a sobreposição do pronome conservador em relação ao inovador implica que o segundo ainda está em um processo de uso não tão difundido, como ocorre na posição de sujeito. Entretanto, os resultados aqui encontrados da variável dependente vão ao encontro de outros trabalhos sociolinguísticos, como de Vianna \& Lopes (2012) e Vitório (2017b), comprovando que há o processo de variação e que o pronome inovador está se implementando na comunidade de fala, mas que ainda é pouco selecionado comparado ao nós.

Para a análise dos dados, selecionamos como variáveis independentes seis grupos de fatores: sexo/gênero, faixa etária, escolaridade, tipos de núcleo, paralelismo formal e relações gramaticais. Após a rodada dos dados, o programa computacional GoldVarb X selecionou como significativas apenas duas variáveis: tipos de núcleo e paralelismo formal. Desse modo, as demais variáveis (sexo/gênero, faixa etária, escolaridade e relações gramaticais) foram selecionadas como não significativas estatisticamente. Neste trabalho, focaremos em apresentar os resultados das variáveis estatisticamente significativas e faremos uma breve discussão sobre as variáveis relações gramaticais e faixa etária, como será feito nas seguintes subseções.

\subsection{Variáveis independentes estatisticamente significativas}

Tipos de núcleo foi a primeira variável selecionada como estatisticamente significativa. Essa variável está relacionada ao núcleo que o pronome se encontra, podendo estar situado tanto no núcleo verbal quanto no nominal ${ }^{2}$. Consideramos para

\footnotetext{
${ }^{2} \mathrm{Nem}$ todas as funções sintáticas ocorrem no núcleo nominal. Sendo o dativo e o acusativo complementos verbais. Já o (oblíquo) complemento e o (oblíquo) adjunto podem ocorrer tanto no núcleo verbal quanto no nominal (VIANNA \& LOPES, 2013).
} 


\section{das Letras}

isso que o pronome inovador se encontra mais presente no núcleo verbal, como no exemplo (5), sendo menos difundido no núcleo nominal, como no exemplo (6), já que, segundo Vianna \& Lopes (2012, p. 141), "as relações internas ao sintagma nominal, principalmente quando são de adjunção (as mais produtivas nos dados), assumem um caráter muito mais fixo (imutável) na organização do sistema, isto é, são relações de caráter essencialmente sintático e não discursivo".

(5) ele levou o dinheiro mas não feriu a gente não agrediu assim agrediu só de boca mas não machucou ninguém x levaram o dinheiro da gente e a rente voltou para a cidade. L53

(6) que num é a família da gente é melhó pra gente do que as mesmas parente L57

Assim, após a rodada dos dados, foi possível obter os seguintes dados:

Gráfico 2: Realização do nós e a gente por tipo de núcleo

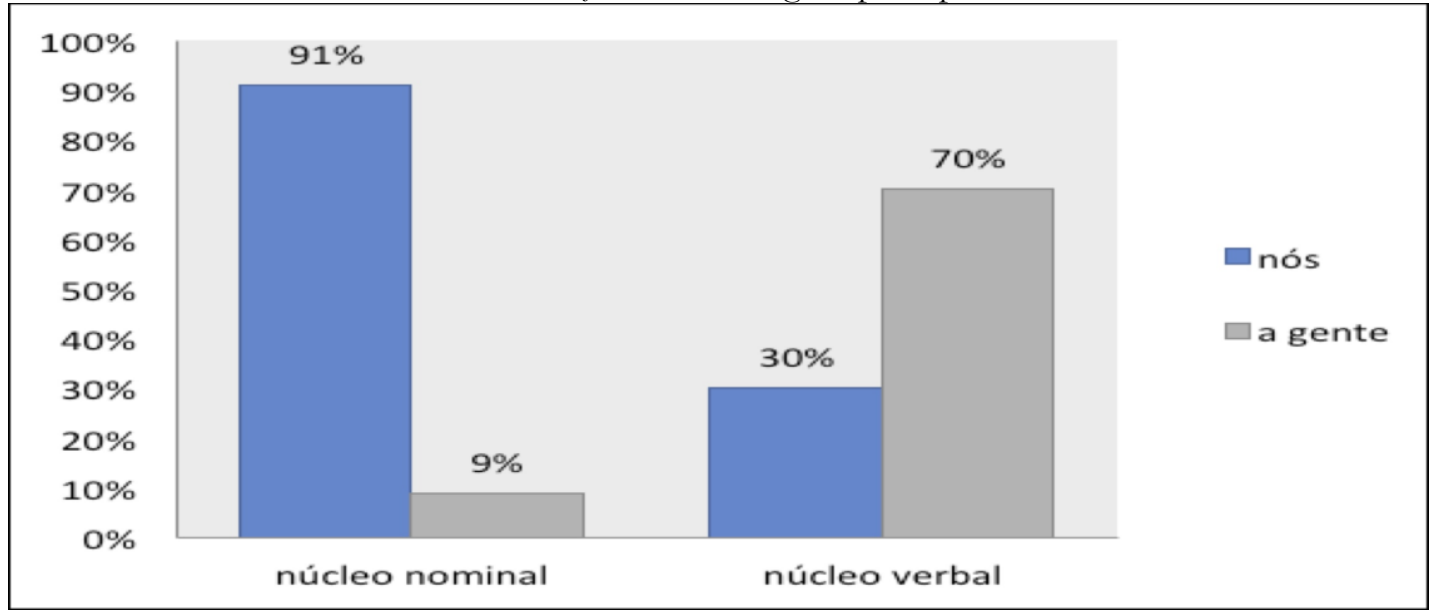

Fonte: elaborado pelos autores

Como podemos observar, a entrada do pronome a gente ocorre mais no núcleo verbal, com um percentual de 70\%, com apenas 30\% do pronome nós. Já, no núcleo nominal, o pronome a gente é menos selecionado, apresentando um percentual de apenas $9 \%$, com o pronome nós apresentando um percentual de $91 \%$. Assim, é no núcleo verbal que o pronome inovador encontra sua porta de entrada nas funções de complemento e adjunto, enquanto, no núcleo nominal, o a gente é desfavorecido, prevalecendo o pronome conservador, conforme tabela 3. 
Tabela 3: Realização do a gente na variável tipo de núcleo

\begin{tabular}{l|c|c}
\hline & Aplic. / Total / Perc. & PR \\
\hline Núcleo verbal & $28 / 40 / 70 \%$ & 0.93 \\
\hline Núcleo nominal & $15 / 170 / 9 \%$ & 0.36 \\
\hline
\end{tabular}

Fonte: elaborado pelos autores

Os dados da tabela 3 mostram que o maior índice de realização para a gente se efetiva no núcleo verbal, com um peso relativo de 0.93 , em comparação com o núcleo nominal, em que o peso relativo é de apenas 0.36 . Tais resultados se relacionam diretamente aos apresentados por Vianna \& Lopes (2012) e Vitório (2017b), comprovando que a porta de entrada do pronome inovador evidencia-se no núcleo verbal, enquanto no nominal há um barramento da variante. Assim, dialogando com Vianna \& Lopes (2012), o pronome a gente está adentrando melhor no núcleo verbal por conter um caráter mais discursivo do que sintático. Isso implica a ideia de que o falante tende a ser mais explícito ao falar uma forma linguística na qual é utilizado o a gente.

A segunda e última variável independente considerada como estatisticamente significativa pelo programa é a variável paralelismo formal. Essa variável implica a ideia de o falante tender a utilizar determinada forma linguística em uma mesma sequência enunciativa. Desse modo, a hipótese é que o falante irá repetir o pronome a gente se, na mesma sequência discursiva, ele a tenha começado com o a gente. Para a análise dessa variável, consideramos os seguintes fatores: realização isolada, como (7); primeiro da série, como (8); antecedido por a gente sujeito, como (9); antecedido por a gente em outras funções, como (10); antecedido por nós sujeito, como (11); e antecedido por nós em outras funções sintáticas, como (12).

(7) uma coisa qui tá próxima, né? mais cedo ou mais tarde acaba batendo na porta da gente L45

(8) bem a questão da onde de violência no nosso estado assim como em outros estados nós não podemos atríbuí a questão do desemprego L46

(9) não não bateu no lado assim da: da trazeira do: do lado do mororista né? mais $\mathrm{x}$ teve susto né? a gente foi devia do carro aí vinha a moto atrás aí - bateu na gente L43 (10) é um assalto e a gente num pôde reagir xx ele levou o dinheiro mas não feriu a gente não agrediu (a gente) assim agrediu (a gente) só de boca mas não machucou ninguém x levaram o dinheiro da gente e a gente voltou pra cidade. L53

(11) tem que que melhorá o nosso nordeste principalmente o sertão onde $\varnothing$ vivemos - ele:: ele ainda é ultrapassado - no que se refere a eleição - é muito comprado mesmo aqui na nossa região a gente vê muito isso - toda eleição - então só queria que acabasse com isso e que o povo se conscientizasse de quem qué realmente o bem deles L62 


\section{das Letras}

(12) eu que fui passeá nos istado de Sergipe e eu conheci cidades muitos menores do que a nossa (cidade) qui é muito mais evoluída e desenvolvida - cidades do tamanho de alguns bairros aqui da nossa cidade - onde prefeitos investem em culutra isportes lazê para os seus habitantis principalmente para os jovens, né? se não investi no jovem na base a violência e o atraso da cidade não vai acaba nunca L69

Gráfico 4: Realizações de nós e a gente por variável paralelismo formal

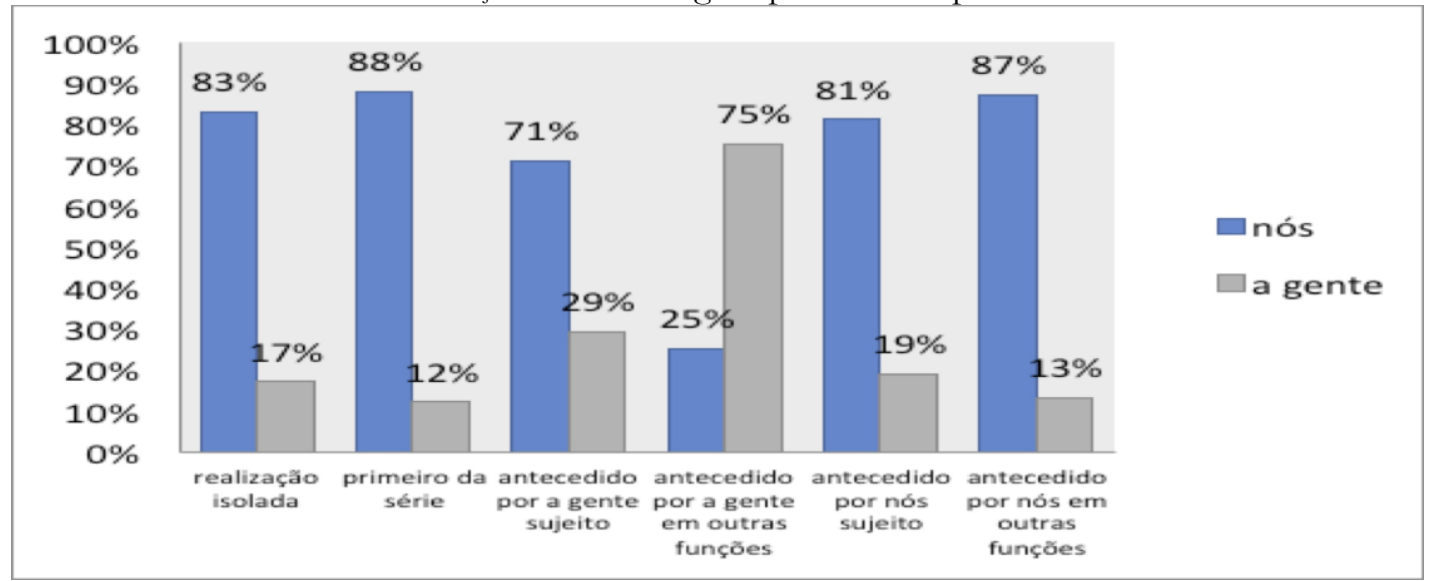

Fonte: elaborado pelos autores

Como podemos observar no gráfico 4, há um alto índice de realização para o pronome nós na maioria das sequências discursivas. O maior índice de realização do nós ocorre no fator primeiro da série - 88\%, seguido do fator antecedido por nós em outras funções sintáticas $-87 \%$, realização isolada $-83 \%$, antecedido por nós sujeito $-81 \%$ e antecedido por a gente sujeito $-71 \%$. O único fator que demonstrou maior realização para o pronome a gente nas funções de não sujeito foi o de antecedido por a gente em outras funções, com um percentual de $75 \%$ para a gente, contra $25 \%$ para o pronome nós, mostrando um favorecimento de a gente nesse contexto.

Isso nos leva a considerar que há um maior peso relacionado à ocorrência de a gente na mesma sequência discursiva na posição de não sujeito. Sobre isso, Ramos, Bezerra \& Rocha (2009, p. 287) falam que "os falantes normalmente elegem como forma para sua primeira referência aquela forma que é predominante em suas realizações e tendem a repeti-la, principalmente quando não há mudança de referente". Assim, compreendemos que houve tais resultados pela ideia de o falante, quando já introduzido essa forma na posição de não sujeito, preservar a forma que já havia sido introduzida por ele, tendo maior aplicabilidade o nós. 


\section{das Letras}

Tabela 4: Realização de a gente na variável paralelismo formal

\begin{tabular}{l|c|c}
\hline & Aplic. / Total / Perc. & PR \\
\hline Realização isolada & $10 / 58 / 17 \%$ & .50 \\
\hline Primeiro da série & $6 / 49 / 12 \%$ & .34 \\
\hline Antecedido por a gente sujeito & $14 / 48 / 29 \%$ & .58 \\
\hline Antecedido por a gente em outas funções sintáticas & $6 / 8 / 75 \%$ & .94 \\
\hline Antecedido por nós sujeito & $3 / 16 / 19 \%$ & .74 \\
\hline Antecedido por nós em outras funções sintáticas & $4 / 31 / 13 \%$ & .36 \\
\hline
\end{tabular}

Fonte: elaborado pelos autores

Os dados da tabela 4 mostram o peso relativo de cada fator de ocorrência. $\mathrm{O}$ fator que possui mais peso para a ocorrência do a gente é o antecedido por a gente em outras funções sintáticas, com peso relativo de 0.94 . Os outros fatores que corroboram com a realização do a gente nas posições de não sujeito foram os de antecedido por a gente sujeito, com peso de 0.58 e a de antecedido por nós sujeito, com peso relativo de 0.74 . Ramos, Bezerra \& Rocha (2009, p. 290) destacam a importância do paralelismo formal para as funções de não sujeito tendo em vista que "[...] a existência de uma forma antecedente de a gente leva à manutenção dessa forma”, revelando que é mais comum o uso do a gente quando ele vem antecedido por a gente.

O contexto de primeiro da série foi o que menos demonstrou influência na realização do a gente, com peso relativo 0.34 , entendendo, assim, que, nesse fator, há maior predominância da variante nós. Os contextos de realização isolada e o antecedido por nós em outras funções sintáticas também funcionam como forma de barrar a variante inovadora, com pesos de 0.50 e 0.36 , respectivamente, concluindo, assim, que, nessas posições, há pouca introdução do a gente.

Os resultados por nós encontrados dialogam com os resultados de Vianna \& Lopes (2012) e Vitório (2017). Desse modo, compreendemos que, além do fator paralelismo formal se mostrar significativo, essa variável implica que há ambientes em que o falante tende a utilizar mais o pronome inovador. Assim, os fatores antecedido por a gente em outras funções sintáticas, antecedido por nós sujeito e antecedido por a gente sujeito desempenham peso fundamental para o uso do a gente na comunidade de fala estudada, representando a ideia de que a variável paralelismo formal é fundamental para implementação de a gente no falar do sertão alagoano. 


\subsection{Nota sobre a variável relações gramaticais}

Como o nosso trabalho se guia através da análise variacionista das formas pronominais nós/a gente nas funções de complemento e adjunto no sertão alagoano, compreendemos que seja importante observar os índices de realização dessas formas pronominais em relação à variável relações gramaticais considerada nesta pesquisa e que foi considerada estatisticamente não significativa, mas relevante nas pesquisas de Vianna \& Lopes (2012) e Vitório (2017b).

Relacionando-se diretamente com a variável tipo de núcleo, essa variável funciona ao redor da perspectiva da função sintática na qual o pronome está inserido, ou seja, as relações gramaticais nas quais os pronomes de 1PP podem assumir. Para isso, selecionamos quatro relações gramaticais, são elas: acusativo (13), dativo (14), (oblíquo) complemento (15) e (oblíquo) adjunto (16). Adotamos aqui os termos apresentados por Vianna \& Lopes (2012), baseados nos pressupostos de Duarte (2003).

(13) São $\mathrm{N}$ fatores que a gente se fô olhá às vezes deixa a gente até para baixo /mais, mas/ sempre tem seus lados positi:vos e são esses que às vezes deixa a gente mais à vontade no que faz L14

(14) Não - porque desde pequenininho que a minha mãe não teve condições de dá o melhó pra gente né? L38

(15) o prefeito aqui é um ladrão - num tem um "fi" da peste certo - pega - o nosso ganha pão aí leva pro curral é cinquenta conto pra soltá - xxx isso aí eles tamém tão errado [...] L4

(16) Rapaz é: - x assim é culpa: também como cê pergunto xx dos governantes na: no nosso estado né? porque se eles investissem ma:is eu tenho certeza que num num tava essa onda de: de criminalidade essa monte de coisa L4

Gráfico 5: Realização do nós e a gente por relação gramatical

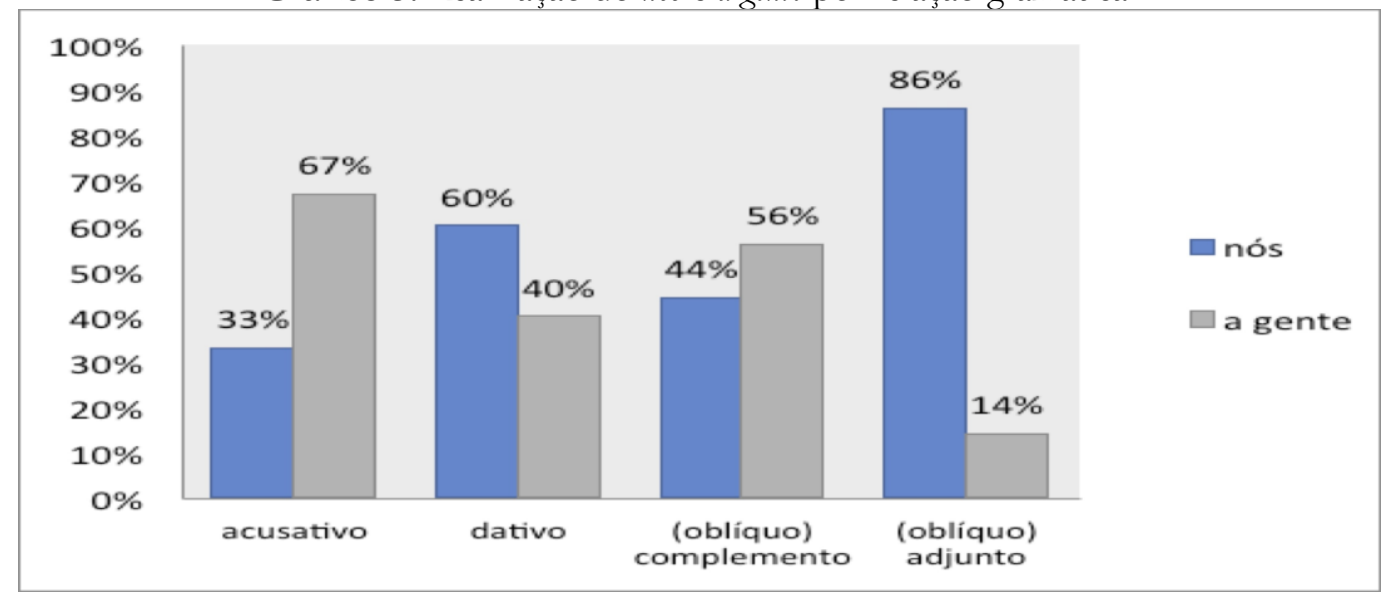

Fonte: elaborado pelos autores 
As relações gramaticais que mais propiciaram a realização do pronome a gente foram as de acusativo, em que foram localizadas 12 realizações de a gente, com $67 \%$, contra 6 realizações de nós, representando $33 \%$, e a de (oblíquo) complemento, localizadas 5 realizações de a gente, com $56 \%$ oposto a 4 realizações de nós, com $44 \%$. Em relação ao uso de nós, a maior ocorrência se deu através da função de (oblíquo) adjunto, representando um total de $86 \%$, com 154 realizações, contra apenas $14 \%$ do a gente, sendo 24 realizações, provando ser a função que mais inibe a entrada do pronome inovador. A função de dativo também propiciou a maior realização do nós, com $60 \%$, sendo 3 realizações, contra $40 \%$ da variante inovadora, sendo 2 realizações.

Realizamos o cruzamento entre as variáveis relações gramaticais e tipos de núcleo, com o intuito de verificar em que contexto sintático a entrada de a gente é mais limitada e observamos, conforme tabela 5 , que é no interior do sintagma nominal na função de (oblíquo) adjunto, com nós apresentando um percentual maior de uso - 89\% e havendo um barramento maior da implementação de a gente. Esses dados corroboram os achados de Vianna \& Lopes (2012) e Vitório (2017b), mostrando, assim, um mesmo comportamento linguístico nas comunidades estudadas.

Tabela 5: Realização de a gente por relações gramaticais e tipos de núcleo

\begin{tabular}{|c|c|c|c|c|c|c|c|c|}
\hline & \multicolumn{2}{|c|}{ Acusativo } & \multicolumn{2}{|c|}{ Dativo } & \multicolumn{2}{|c|}{$\begin{array}{c}\text { (oblíquo) } \\
\text { Complemento }\end{array}$} & \multicolumn{2}{|c|}{ (oblíquo) Adjunto } \\
\hline & nós & a gente & nós & a gente & nós & a gente & nós & a gente \\
\hline Núcleo & & & & & $3 / 170$ & $2 / 170$ & $152 / 170$ & $13 / 170$ \\
\hline Nominal & - & - & - & - & $2 \%$ & $1 \%$ & $89 \%$ & $8 \%$ \\
\hline Núcleo & $6 / 40$ & $12 / 40$ & $3 / 40$ & $2 / 40$ & $1 / 40$ & $3 / 40$ & $2 / 40$ & $11 / 40$ \\
\hline verbal & $15 \%$ & $30 \%$ & $7 \%$ & $5 \%$ & $3 \%$ & $7 \%$ & $5 \%$ & $28 \%$ \\
\hline
\end{tabular}

Fonte: elaborado pelo autor

Esses dados evidenciam a ideia de que, além de o pronome a gente estar melhor se inserindo na língua através do núcleo verbal, funções sintáticas também estão favorecendo a sua entrada no Português analisado na região, mesmo com a variável relações gramaticais tendo sido descartada como significativa pelo programa. Desse modo, entendemos que há funções gramaticais que possuem mais peso na ocorrência dos pronomes de $1 \mathrm{PP}$.

\subsection{Mudança em curso ou variação estável?}

Como a variável faixa etária foi estatisticamente não significativa, não fizemos uma análise dos dados obtidos. Entretanto, como é através dessa variável, do recorte sincrônico, que podemos atestar uma mudança em tempo aparente, fazemos aqui um 


\section{das Letras}

breve comentário sobre os resultados obtidos para a variação nós e a gente não sujeito na comunidade de fala do sertão alagoano. Observemos os resultados da variável faixa etária no gráfico 6 .

Gráfico 6: Realização de nós e a gente na variável faixa etária

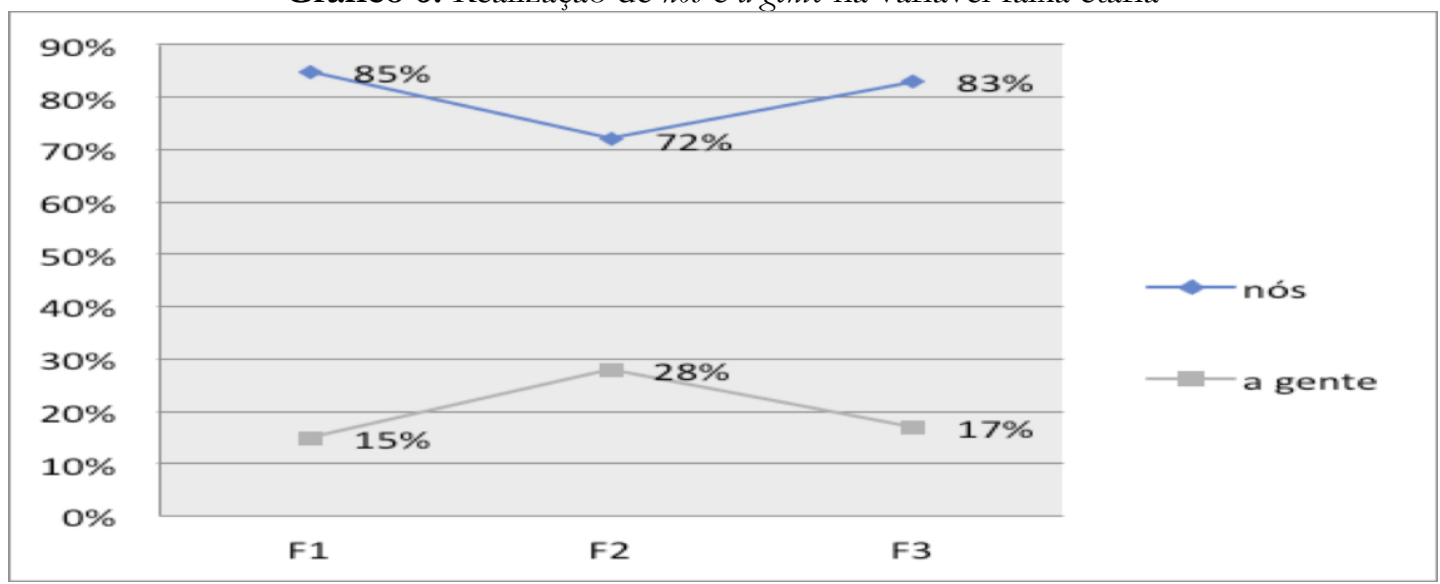

Fonte: elaborado pelos autores

Seguindo o que prega a Teoria da Variação e Mudança (LABOV, 2008) sobre a perspectiva de observar a mudança linguística através da metodologia de tempo aparente, os dados apontam que estamos diante de uma variação estável, tendo em vista que, enquanto há um acréscimo de a gente na F2 - 28\%, nas F1 e F3, temos um decréscimo dessa variante $-15 \%$ e $17 \%$, respectivamente, permanecendo, assim, a maior incidência da variante conservadora.

A relação de estabilidade das variantes (a situação de contemporização) avultará, se entre a regra variável e a faixa etária dos informantes não houver qualquer tipo de correlação. Se, por outro lado, o uso da variante mais inovadora for mais frequente entre os jovens, decrescendo em relação à idade dos outros informantes, você terá presenciado uma situação de mudança em progresso, a tal relação de duelo de morte [...]. (TARALLO, 2003, p. 65).

Nesse sentido, os resultados para o uso de nós e a gente nas funções de não sujeito no sertão alagoano atestam que, através do recorte por tempo aparente, não há uma mudança em curso em direção ao uso de a gente. Esses números podem ser um indício de que haja aqui uma interferência do mercado de trabalho, uma vez que pesquisas sociolinguísticas mostram que a gente é a variante selecionada nas variedades urbanas do português brasileiro, sendo não estigmatizada socialmente.

\section{CONSIDERAÇÕES FINAIS}

Em nossa pesquisa, analisamos o processo de variação entre os pronomes de $1 \mathrm{PP}$ nós e a gente nas funções de complemento e adjunto, com o objetivo de observar se, no falar do sertão alagoano, há essa troca pronominal. Após a obtenção dos dados, 
computamos 210 realizações dos pronomes de 1 PP nas funções de não sujeito, sendo 167 para nós e 43 para a gente, confirmando a nossa primeira hipótese de que há variação entre os pronomes de $1 \mathrm{PP}$ nas funções de não sujeito no sertão alagoano. Mesmo assim, o pronome nós teve maior realização nessas funções, diferente do índice de realização na função de sujeito.

Além disso, consideramos que havia fatores linguísticos e/ou sociais que condicionariam o uso da variante inovadora. Após a rodada dos dados, todas as variáveis sociais foram descartadas como estatisticamente significativas, implicando que as variáveis como sexo/gênero, faixa etária e escolaridade não possuem peso significativo no processo de variação por nós analisado. Já em relação as variáveis linguísticas, o programa considerou duas e descartou uma. As variáveis tipos de núcleo e paralelismo formal foram as únicas vistas como estatisticamente significativas, enquanto à variável relações gramaticais foi descartada. Assim, compreendemos que os condicionadores para essa variação se encontram apenas no nível da língua.

Quanto ao fato das variáveis sociais terem sido descartadas na análise dos dados, temos uma ideia de que, mesmo sendo a variante não padrão, o a gente pode não sofrer estigma social nessas posições, entretanto, para que possamos comprovar isso, é preciso que seja feita uma pesquisa avaliativa com os falantes da região para mesurarmos se estamos diante de um estereótipo, marcador ou indicador linguístico, conforme pontua Labov (2008).

Assim, concluímos que, embora haja o processo de variação entre nós e a gente nas funções de não sujeito no sertão alagoano, o pronome nós ainda é o mais selecionado pelos falantes. Além disso, os fatores sociais não interferem diretamente no uso dessas variantes, prevalecendo como fator condicionante apenas variáveis linguísticas. Mesmo havendo a variação, estamos diante de uma variação estável, tendo em vista os resultados na variável faixa etária. Desse modo, o nosso estudo levou à contribuição para os estudos linguísticos feitos sobre a língua, principalmente ajudando a traçar uma parte do perfil sociolinguístico da região do sertão alagoano.

\section{REFERÊNCIAS}

DUARTE, I. Relações gramaticais, esquemas relacionais e ordem de palavras. In: MIRA MATEUS, M. H. Gramática da Lingua Portuguesa. Lisboa: Caminho, 2003, p. 277-321.

FEITOSA, J. A variação nós e a gente na posição de sujeito no sertão alagoano. Monografia (Letras) - Universidade Federal de Alagoas, Delmiro Gouveia, 2017.

LABOV, W. Padrões Sociolinguísticos. São Paulo: Parábola Editorial, 2008 [1972].

LOPES, C. De gente para a gente: o século XIX como fase de transição. In: ALKMIM, T. (Org.). Para a História do Português Brasileiro - Novos Estudos. São Paulo: Humanitas, 2002, p. 25-46.

. A inserção de a gente no quadro pronominal do português. Madrid: Iberoamericana, 2003. 
- A gramaticalização de a gente em português em tempo real de longa e de curta duração: retenção e mudança na especificação dos traços intrínsecos. Fórum Lingüístico, Florianópolis, v. 4, n.1, 2004, p. $47-80$.

PORTO SILVA, S. A variação de você e cê na fala dos sertanejos alagoanos. Monografia (Letras) - Universidade Federal de Alagoas, Delmiro Gouveia, 2017.

RAMOS, C.; BEZERRA, J.; ROCHA, M. Do nosso cotidiano ou do cotidiano da gente? Um estudo da alternância nós/a gente no português do Maranhão. Revista Signum. Londrina, v. 12, n. 1, p. 279-292, jul. 2009.

SANKOFF, D.; TAGLIAMONTE, S.; SMITH, E. Goldvarb X: a variable rule application for Macitosh and Windows. Departamento of Linguistics, University of Toronto, 2005.

SILVA, L. O uso do pronome nós e da variante a gente na posição de sujeito entre os falantes não escolarizados do alto sertão alagoano. Monografia (Letras) - Universidade Federal de Alagoas, Delmiro Gouveia, 2017.

TARALLO, F. A pesquisa sociolinguistica. Editora Ática: São Paulo, 2003.

VIANNA, J; LOPES, C. A competição entre nós e a gente nas funções de complemento e adjunto: desvendando outras portas de entrada para o pronome inovador. Caligrama, Belo Horizonte, v. 17, n. 2, p. 137-161, 2012.

Implementação de a gente nas funções de acusativo, dativo e oblíquo: reflexões, propostas e primeiros resultados. Lingüistica 29 (1), junio 2013

VITÓRIO, E. A língua usada no sertão alagoano: constituição da amostra. Trabalho apresentado no III Estudos em Linguagem do Sertão. Delmiro Gouveia, jun. 2017a.

A realização dos pronomes nós e a gente na função de sujeito e nas funções de complemento e adjunto na cidade de Maceio/AL. Letrônica. Porto Alegre, v. 10, n. 1, p. 122-138, janeiro-junho, 2017b. 